Original Article

\title{
Early mobilisation of patients with community-acquired pneumonia reduce length of hospitalisation-a pilot study
}

\author{
Dorte Melgaard ${ }^{1,2)^{*}}$, Ulrik Baandrup ${ }^{1,2)}$, Martin Bøgsted ${ }^{3,4)}$, Mette Dahl Bendtsen ${ }^{3,4)}$, \\ Morten TANGe Kristensen ${ }^{5)}$ \\ 1) Center for Clinical Research, North Denmark Regional Hospital: Bispensgade 37, \\ DK-9800 Hjørring, Denmark \\ 2) Department of Clinical Medicine, Aalborg University, Denmark \\ 3) Department of Haematology, Aalborg University Hospital, Denmark \\ 4) Department of Clinical Medicine, Aalborg University Hospital, Denmark \\ 5) Physical Medicine and Rehabilitation Research-Copenhagen (PMR-C), Departments of \\ Physiotherapy and Orthopaedic Surgery, Copenhagen University Hospital, Denmark
}

\begin{abstract}
Purpose] To examine if length of stay was reduced following an early mobilisation programme in patients with community-acquired pneumonia, and secondary, if such a program influenced short-term rehospitalisation and mortality rates. [Participants and Methods] Ninety seven consecutive patients (51\% men; over all mean $\pm \mathrm{SD}$ age $71.9 \pm 16.5$ years) with community-acquired pneumonia were included in the intervention group, and compared with a historical control group of 97 patients, matching at case level. Early mobilisation was defined as more than 20 minutes out of bed within 24 hours of hospitalisation. [Results] Eighty out of 97 patients in the intervention group were mobilised within 24 hours and length of stay for all patients was reduced with an average of 1.5 (95\% CI: $-0.2 ; 3.2)$ days compared to the control group. There was no significant difference between the two groups according to 30 -day rehospitalisation and mortality. [Conclusion] An early mobilisation program seem to reduce the length of stay for patients with community-acquired pneumonia, and without an increase in short-term mortality and re-hospitalisation rates.

Key words: Mobilisation, Pneumonia, Length of hospitalisation
\end{abstract}

(This article was submitted Jan. 26, 2018, and was accepted Apr. 25, 2018)

\section{INTRODUCTION}

Community-acquired pneumonia (CAP) remains a leading cause of mortality all over the world, and elderly people are particularly at risk ${ }^{1,2)}$. CAP is an acute infection of the pulmonary parenchyma associated with clinical features (coughs, fevers, sputum production, and pleuritic chest pain) and accompanied by the presence of an acute infiltrate demonstrated on a chest radiograph — with or without supporting microbiological data ${ }^{3)}$.

The incidence of adults hospitalised with pneumonia has increased during the last few decades ${ }^{4,5)}$. Risk factors for pneumonia include age, male gender, a general decrease in functional level, and malnutrition ${ }^{6,7)}$. The rehospitalisation rate within 30 days of discharge for patients with CAP is high, as indicated in a Danish study with a rate of $12.3 \%{ }^{8}$.

Several studies document the effects of early mobilisation (EM) of patients in the intensive care unit (ICU) and in surgery units, and seems as a safe and effective intervention that can have a significant impact on functional outcomes ${ }^{9-13)}$. However, to our knowledge, only one study documents the effects of early mobilisation of patients with CAP ${ }^{14}$. This multicentre study

*Corresponding author. Dorte Melgaard (E-mail: dmk@rn.dk)

(C2018 The Society of Physical Therapy Science. Published by IPEC Inc.

(c) (1) $\odot$ This is an open-access article distributed under the terms of the Creative Commons Attribution Non-Commercial No Derivatives CC. ${ }_{\text {BY }}$ ND (by-nc-nd) License. (CC-BY-NC-ND 4.0: https://creativecommons.org/licenses/by-nc-nd/4.0/) 
included 458 patients with CAP, and randomised to EM or usual care in different settings, and with a reduced length of stay (LOS), by an average of 1.1 days in the EM group compared to the usual care group ${ }^{14)}$.

The primary aim of this study was therefore to evaluate if a similar EM programme of patients with CAP, when instigated in another setting would lead to a similar reduction in LOS. The secondary aim was to evaluate mortality during hospitalisation in addition to mortality and rehospitalisation within 30 days post-discharge.

The hypothesis was that patients hospitalised for CAP, mobilised within the first 24 hours, and following a progressive mobilisation programme during hospitalisation, could be discharged earlier, and without increased mortality and pulmonary related rehospitalisation rates.

\section{PARTICIPANTS AND METHODS}

Patients hospitalised with CAP at North Denmark Regional Hospital, a 385-bed public hospital, were consecutively included over the period from September 1, 2012 to February 28, 2013. Inclusion criteria for the early mobilisation group (EMG) were age $\geq 18$ years old, CAP and admission to the Department of Lung Medicine. Patients receiving palliative treatment, diagnosed with dementia, transferred from another department or hospital, transferred to another department, or hospitalised from Friday afternoon to Sunday noon, were excluded.

A historical control group (CG) was matched with the EMG at case level according to gender, age ( \pm 2 years), hospitalisation due to CAP in the same ward, and being discharged from this ward in the period from September 1, 2011 to February 28, 2012. The exclusion criteria were the same and there was no change in medical guidelines for the two groups. The study was registered with the Danish Data Protection Authority (2008-58-0028). All patients were informed of the project; written informed consent was not requested according to the local Ethics Committee.

Demographic data on age, gender, admission date, discharge date, first acute rehospitalisation and mortality within 30 days after discharge were recorded from the National Patient Register. Medical information was recorded from the electronical patient record, namely CRP, temperature, urea, respiratory rate, confusion, blood pressure at time of hospitalisation, time from admittance to initiation of antibiotic therapy, use of corticosteroids, medication by discharge, and comorbidity ${ }^{15}$.

The severity of pneumonia was assessed with the CURB6 $5^{16,17)}$, which consists of five factors: confusion, urea, respiratory rate, blood pressure, and age $>65$ years. Each factor scores 1 point, up to a maximum score of 5 points. The CURB 65 predicts mortality at 30 days, and mortality increases as the score increases in patients with $\mathrm{CAP}^{16)}$. Comorbidity was assessed with the Charlson Comorbidity Index ${ }^{18,19)}$. Each condition is assigned a score of 1, 2, 3, or 6, depending on the risk of mortality associated with each. Scores are summed to a score between 0-31 to provide a total score predicting mortality. The higher the score, the higher the risk of mortality. For the EMG, the objectively assessed Cumulated Ambulation Score $(\mathrm{CAS})^{20)}$, the prehospital New Mobility Score (NMS) ${ }^{21}$. The CAS describes the patients' independence in three activities: 1) getting in and out of bed; 2) sitting down and standing up from a chair with arms; and 3) being able to walk with or without an appropriate walking aid. The score for each activity is cumulated to provide a daily score between 0 and 6 , with 6 points indicating basic mobility independency ${ }^{20)}$. The NMS was used to describe the patients' pre-hospital functional level, assessed as the patient reported indoor, outdoor, and during shopping walking ability one week before hospitalisation. Each activity is scored from $0-3$ and cumulated to a score between 0 and 9, with high scores indicating a high level of function ${ }^{22}$. Three experienced physiotherapists, who received training in using the tests, mobilised the patients within 24 hours of hospitalisation, if at all possible. EM was defined as movement out of bed with a change from the horizontal to the upright position for at least 20 minutes, and progressed during the entire hospital stay. The level of mobilisation at each session was individual and adjusted to the patients' functional level and motivation. Physiotherapy was offered daily on weekdays. Patients in the control group were mobilised by physiotherapists or nurses, but all patients were not mobilised and those who were mobilised were not systematically mobilised within 24 hours from admission.

Patients were discharged after they had received antibiotics orally, were considered clinically stable, and were independently mobile as recommended by the Danish Society of Respiratory Medicine ${ }^{23}$. Rehospitalisation was defined as admission within 30 days of discharge as a result of pneumonia or any other somatic disease, in the Northern Region of Denmark.

Descriptive statistics included the number and percentage of patients for categorical variables, and mean $( \pm$ standard deviation) for continuous variables. Differences between the two study groups were analysed using Fisher's exact test for categorical variables, and the two-sample t-test for continuous variables. Even though the distributions of some clinical variables were positively skewed, the number of observations per group was sufficiently large to justify using the t-test without a log transformation. The Kaplan-Meier method was applied to estimate the mean LOS with discharge as the event, and censoring for mortality. Z-tests were conducted to test for differences in the LOS between the two groups. Log rank tests were applied to test for differences in survival and rehospitalisation between the two groups. Throughout the analyses, $95 \%$ confidence intervals (CI) were reported and a p-value $<0.05$ was considered statistically significant. Statistical analyses were performed using Stata Version 13.1 software (Stata Corporation, College Station, TX, USA).

\section{RESULTS}

We enrolled 111 consecutive patients in the EMG of which 14 patients (71.4\% male, mean age 77.6) were excluded due 
Table 1. Characteristics of patients

\begin{tabular}{lccc}
\hline & $\begin{array}{c}\text { Early mobilisation group } \\
(\mathrm{N}=97)\end{array}$ & $\begin{array}{c}\text { Control group } \\
(\mathrm{N}=97)\end{array}$ & p-value \\
\hline Age (years), mean \pm SD & $71.9 \pm 16.5$ & $71.9 \pm 16.5$ & 0.982 \\
Gender & & & \\
$\quad$ Male & $51(52.6)$ & $51(52.6)$ & 1.000 \\
New Mobility Score, mean \pm SD & $6.6 \pm 3.2$ & & \\
CURB65 scores & & & \\
0 & $15(18.1)$ & $16(19.1)$ & \\
1 & $29(34.9)$ & $26(31.0)$ & \\
2 & $26(31.3)$ & $30(35.7)$ & \\
3 & $13(15.7)$ & $10(11.9)$ & \\
4 & $0(0)$ & $1(1.2)$ & \\
5 & $0(0)$ & $1(1.2)$ & \\
$\quad$ Missing & $14(14.4)$ & $13(13.4)$ & 0.839 \\
Time to antibiotic & $9.97( \pm 6.50)$ & $10.02( \pm 7.69)$ & 0.963 \\
Time to corticosteroids & $53(54.64)$ & $48(49.48)$ & 0.566 \\
Charlson Comorbidity Index & $4.6 \pm 2.0$ & $4.5 \pm 1.8$ & 0.910 \\
COPD & $39(40.2)$ & $54(55.7)$ & \\
\hline
\end{tabular}

Data are numbers (\%), otherwise as stated.

Table 2. Length of stay by CURB65 and COPD

\begin{tabular}{|c|c|c|c|c|c|c|c|c|c|c|}
\hline \multirow[b]{2}{*}{ CURB65 } & \multicolumn{4}{|c|}{ EMG } & \multicolumn{3}{|c|}{ CG } & \multirow[b]{2}{*}{$\begin{array}{c}\text { Diff } \\
(\text { EMG-CG) }\end{array}$} & \multirow[b]{2}{*}{$95 \%$ CI } & \multirow[b]{2}{*}{$\mathrm{p}$-value } \\
\hline & $\mathrm{n}$ & $\begin{array}{l}\text { LOS } \\
\text { Mean }\end{array}$ & $95 \%$ CI & $\begin{array}{c}\text { Compliance to } \\
\text { early mobilisation }\end{array}$ & $\mathrm{n}$ & $\begin{array}{l}\text { LOS } \\
\text { Mean }\end{array}$ & $95 \%$ CI & & & \\
\hline 0 & 15 & 3.6 & $2.2 ; 4.9$ & $14(93.3 \%)$ & 16 & 4.3 & $3.2 ; 5.5$ & -0.8 & $-2.6 ; 1.0$ & 0.381 \\
\hline 1 & 29 & 5.4 & $3.9 ; 6.9$ & $25(82.2 \%)$ & 26 & 7.1 & $3.6 ; 10.6$ & -1.7 & $-5.5 ; 2.1$ & 0.379 \\
\hline 2 & 26 & 5.0 & $4.0 ; 6.1$ & $22(84.6 \%)$ & 30 & 8.1 & $5.3 ; 10.9$ & -3.1 & $-6.1 ; 0.1$ & 0.041 \\
\hline $3^{*}$ & 13 & 8.9 & $5.4 ; 12.4$ & $9(69.2 \%)$ & 10 & $7.1^{*}$ & $4.7 ; 9.5$ & 1.7 & $-2,5 ; 6.0$ & 0.419 \\
\hline Missing & 14 & 1.8 & $-2.42 ; 0.40$ & $10(71.4 \%)$ & 15 & 2.8 & $-2.47 ; 0.45$ & 1.0 & & 0.155 \\
\hline COPD & 39 & 4.3 & $3.5 ; 5.1$ & $33(84.6 \%)$ & 54 & 6.4 & $4.7 ; 8.0$ & -2.1 & $-3.9 ;-0.2$ & 0.028 \\
\hline
\end{tabular}

*Two patients with respectively CURB65 of 4 and 5 points included.

to transfer to another department for further rehabilitation or to the ICU. The patients in the EMG and the CG were similar in age, gender, severity of pneumonia (CURB65), Charlson Comorbidity Index, time from admittance to initiation of antibiotic therapy and use of corticosteroids, while fewer patients in the EMG suffered from COPD (Table 1). Eighty out of 97 patients in the intervention group were mobilised within 24 hours. There are missing CURB65 data for 14 patients in the IG versus 13 patients in the CG; this is primarily due to the missing registration of blood urea nitrogen.

Patients in the EMG were discharged after an estimated mean of 5.0 days (CI: 4.13; 5.85) compared to 6.5 days (CI: 5.1; 7.9) for the CG, length of stay for all patients was reduced with an average of 1.5 (95\% CI: $-3.2 ; 0.2)$ days compared to the control group. A Z-test for the difference between the EMG and CG yielded a p value of 0.077 .

From winter 2011/2012 to winter 2012/2013, the mean LOS for all patients in the department decreased from an average of 4.75 days to 4.68 days. This difference is not considered important and therefore, it has been disregarded.

In the EMG, patients with a CURB65 score of 0-2 had a shorter LOS compared to patients in the CG, and significant $(p=0.04)$ for patients with a CURB65 score of $2(p=0.041)$ (Table 2). At the same time, patients in the EMG with COPD stayed an average of 2.1 days shorter $(\mathrm{p}=0.028)$ in hospital than those in the CG with COPD (Table 2).

In the EMG, four patients $(4.1 \%)$ died during hospitalisation, compared to seven patients $(7.2 \%)$ in the $\mathrm{CG}(\mathrm{p}=0.351)$ (Table 3). Four out of 93 patients (4.3\%) in the EMG versus 3 out of 90 patients $(3.3 \%)$ in the CG died within the 30 -day post-discharge follow-up period $(\mathrm{p}=0.738)$.

In the EMG, 19 out of 93 (20.4\%) patients were re-hospitalised within 30 days post-discharge compared to 13 out of 90 $(14.4 \%)$ in the CG $(\mathrm{p}=0.274)$, as illustrated in Table 4. However, five of the patients in the EMG were re-hospitalised due to diseases other than lung-related disorders e.g. aortic stenosis and cancer, as compared to one patient in the CG who was re-hospitalised due to pancreatitis. 
Table 3. Association with mortality during hospitalisation and within 30 days post-discharge

\begin{tabular}{|c|c|c|c|c|}
\hline \multirow[b]{2}{*}{ During hospitalisation } & \multicolumn{2}{|c|}{ EMG } & \multicolumn{2}{|c|}{$\mathrm{CG}$} \\
\hline & $\begin{array}{c}\text { Dead } \\
\mathrm{n}=4(4.1)\end{array}$ & $\begin{array}{c}\text { Alive } \\
\mathrm{n}=93(95.9)\end{array}$ & $\begin{array}{c}\text { Dead } \\
\mathrm{n}=7(7.2)\end{array}$ & $\begin{array}{c}\text { Alive } \\
\mathrm{n}=90(92.8)\end{array}$ \\
\hline \multicolumn{5}{|l|}{ Age } \\
\hline$<70$ years & $0(0)$ & $36(38.7)$ & $2(28.6)$ & $33(36.7)$ \\
\hline$\geq 70$ years & $4(100)$ & $57(61.3)$ & $5(71.4)$ & $57(61.3)$ \\
\hline \multicolumn{5}{|l|}{ Gender } \\
\hline Male & $2(50)$ & $49(52.7)$ & $4(57.1)$ & $47(52.2)$ \\
\hline \multicolumn{5}{|l|}{ New mobility score } \\
\hline NMS 0-8 & $4(100)$ & $38(41.3)$ & & \\
\hline NMS 9 & $0(0)$ & $54(58.7)$ & & \\
\hline \multicolumn{5}{|l|}{ CURB65 } \\
\hline 0 & $0(0)$ & $15(18.8)$ & $0(0)$ & $16(20.3)$ \\
\hline 1 & $0(0)$ & $29(36.3)$ & $1(20.0)$ & $25(31.7)$ \\
\hline 2 & $1(33.3)$ & $25(31.3)$ & $2(40.0)$ & $28(35.4)$ \\
\hline $3^{*}$ & $2(66.7)$ & $11(13.8)$ & $2(40.0)$ & $10(12.7)$ \\
\hline Charlson comorbidity index & $5.5 \pm 1$ & $4.5 \pm 2.0$ & $5.4 \pm 1.0$ & $4.4 \pm 1.9$ \\
\hline 30 days after discharge & $\mathrm{n}=4(4.3)$ & $\mathrm{n}=89(95.7)$ & $\mathrm{n}=3(3.3)$ & $\mathrm{n}=87(96.7)$ \\
\hline \multicolumn{5}{|l|}{ Age } \\
\hline$<70$ years & $0(0)$ & $36(40.5)$ & $1(33.3)$ & $32(36.8)$ \\
\hline$\geq 70$ years & $4(100)$ & $53(59.6)$ & $2(66.7)$ & $55(63.2)$ \\
\hline \multicolumn{5}{|l|}{ Gender } \\
\hline Male & $1(25)$ & $48(53.9)$ & $2(66.7)$ & $45(51.7)$ \\
\hline \multicolumn{5}{|l|}{ New mobility score } \\
\hline NMS 0-8 & $3(75.0)$ & $35(39.8)$ & & \\
\hline NMS 9 & $1(25.0)$ & $53(60.2)$ & & \\
\hline \multicolumn{5}{|l|}{ CURB65 } \\
\hline 0 & 0 & $15(19.5)$ & 0 & $16(21.1)$ \\
\hline 1 & $2(66.7)$ & $27(35.1)$ & $1(33.3)$ & $24(31.6)$ \\
\hline 2 & 0 & $25(32.5)$ & $2(66.7)$ & $26(34.2)$ \\
\hline $3^{*}$ & $1(33.3)$ & $10(13.0)$ & 0 & $10(13.2)$ \\
\hline Charlson comorbidity index & $6.5 \pm 3.7$ & $4.4 \pm 1.9$ & $4 \pm 1.7$ & $4.5 \pm 1.9$ \\
\hline
\end{tabular}

Data are reported as numbers (\%), otherwise as stated.

*Two patients with respectively CURB65 of 4 and 5 points included. 
Table 4. Association with rehospitalisation within 30 days from discharge

\begin{tabular}{|c|c|c|c|c|c|c|}
\hline & \multicolumn{2}{|c|}{ EMG } & \multirow[b]{2}{*}{$\mathrm{p}$ value } & \multicolumn{2}{|c|}{$\mathrm{CG}$} & \multirow[b]{2}{*}{$\mathrm{p}$ value } \\
\hline & $\begin{array}{c}\text { Rehospitalised } \\
\mathrm{n}=19(20.4)\end{array}$ & $\begin{array}{c}\text { Not rehospitalised } \\
n=74 \text { (79.6) }\end{array}$ & & $\begin{array}{c}\text { Rehospitalised } \\
n=13(14.4)\end{array}$ & $\begin{array}{c}\text { Not rehospitalised } \\
\mathrm{n}=77(85.6)\end{array}$ & \\
\hline \multicolumn{7}{|l|}{ Age } \\
\hline$<70$ years & $6(31.6)$ & $30(40.5)$ & & $6(46.2)$ & $27(35.1)$ & \\
\hline$\geq 70$ years & $13(68.4)$ & $44(59.5)$ & 0.600 & $7(53.9)$ & $50(64.9)$ & 0.537 \\
\hline \multicolumn{7}{|l|}{ Gender } \\
\hline Male & $9(47.4)$ & $40(54.1)$ & 0.618 & $10(76.9)$ & $37(48.1)$ & 0.073 \\
\hline \multicolumn{7}{|l|}{ New Mobility Score } \\
\hline NMS 0-8 & $12(66.7)$ & $26(35.1)$ & 0.018 & & & \\
\hline NMS 9 & $6(33.3)$ & $48(64.9)$ & & & & \\
\hline \multicolumn{7}{|l|}{ CURB65 } \\
\hline 0 & $3(15.8)$ & $12(19.7)$ & & $4(30.8)$ & $12(18.2)$ & \\
\hline 1 & $8(42.1)$ & $21(34.4)$ & & $2(15.4)$ & $23(34.9)$ & \\
\hline 2 & $6(31.6)$ & $19(31.2)$ & & $5(38.5)$ & $23(34.9)$ & \\
\hline $3^{*}$ & $2(10.5)$ & $9(14.8)$ & 0.964 & $2(15.4)$ & $8(12.1)$ & 0.482 \\
\hline Missing & $3(21.4)$ & $11(78.6)$ & & $2(15.4)$ & $11(84.6)$ & \\
\hline CCI (mean) & $4.5(3.6 ; 5.4)$ & $4.5(4.0 ; 5.0)$ & 0.939 & $4.5(3.4 ; 5.7)$ & $4.4(4.0 ; 4.9)$ & 0.885 \\
\hline COPD & $10(52.6)$ & $28(37.8)$ & 0.299 & $7(53.9)$ & $41(53.3)$ & 1.000 \\
\hline LOS (days) & $5.6(3.8 ; 7.4)$ & $4.4(3.6 ; 5.2)$ & 0.247 & $6.7(4.3 ; 9.1)$ & $5.8(4.4 ; 7.3)$ & 0.529 \\
\hline \multicolumn{7}{|c|}{ Cause for rehospitalisation } \\
\hline Pneumonia, COPD & $14(73.7)$ & & & $12(92.3)$ & & \\
\hline Other diseases & $5(26.3)$ & & & $1(7.7)$ & & \\
\hline
\end{tabular}

Data are reported as numbers (\%), otherwise as stated.

*Two patients with respectively CURB65 of 4 and 5 points included.

\section{DISCUSSION}

The present study shows a clear tendency towards a shorter LOS following an early systematic, progressive physiotherapeutic mobilisation programme, compared to a usual care group of patients with CAP.

Several studies document that EM of patients in ICU lead to significant decreases in $\operatorname{LOS}^{9,10,24-26)}$, but the evidence for EM of patients with CAP is still limited Thus, as previously mentioned, there is only one RCT conducted in the US that reported a reduced LOS of 1.1 days for patients with CAP following an EM programme ${ }^{14}$. Our finding of an average 1.5-day reduction is in accordance with this and adds to the currently sparse knowledge of the positive effects of early mobilisation on the LOS for patients with CAP and without an increase in short-term re-hospitalisation and mortality.

We also found an association between the CURB65 score and the LOS for both the EMG and CG group. Interestingly, patients with a CURB65 score of 2 seem to benefit the most from the EM program, as indicated with an average reduction in the LOS of 2.7 days compared to the CG. This finding appears to correspond to those with a Pneumonia Severity Index score of 3 for patients in the EM group in the study by Mundy et al ${ }^{14)}$. However, this comparison should be interpreted with caution due to the different score systems used.

The in-hospital mortality rate of $4.1 \%$ in the EMG versus $7.2 \%$ in the CG in the present study is low compared to that reported from a Danish register study showing an in-hospital mortality rate of $11.5 \%{ }^{8}$. The corresponding 30 -day postdischarge mortality rate was $16.2 \%$ in the Danish register study, compared to $4.3 \%$ in the EMG and $3.3 \%$ in the CG, in the present study. The lower mortality rates in the present study can possible be explained by the fact that patients with very severe CAP are included neither in the present study nor in the study by Mundy et al. ${ }^{14)}$, due to transfer to the ICU. The mortality during hospitalisation in the study by Mundy et al. ${ }^{14)}$ was lower in the IG than in the CG, but as in the present study, no significant difference was seen for mortality during hospitalisation nor was there any difference 30 days post-discharge.

The post-discharge rehospitalisation rates of $20.4 \%$ in the EMG and $14.4 \%$ in the CG in the present study is higher than that of the abovementioned Danish register study where it was $12.3 \%{ }^{8)}$. A lover functional level before admission appears to be the most important risk factor for rehospitalisation in the EMG. The frequency of rehospitalisation was higher in the EMG even though it was not significant, and the difference was primarily due to patients being rehospitalised due to diseases unrelated to the lungs.

The strength of this study is that it consecutively included a representative sample of patients hospitalised with CAP. Another strength is that the two groups were matched at case level, according to age and gender but also to time to antibiotic therapy and the use of corticosteroids that can influence the LOS significantly ${ }^{27-32)}$. 
Weaknesses are the non-randomised design with a historical CG, that data of the pre-admittance functional level was not available in the CG, and that fewer patients by coincidence suffered from COPD in the EMG. Still, patients with COPD in the EMG had shorter LOS as compared to those in the CG. Another limitation was that CURB65 scores were missing for some patients, but similarly in both groups and with similar outcomes. Planning the study, we considered a randomised controlled design, but there are additional challenges to performing such a trial ${ }^{33}$. Thus, treating patients hospitalised for the same reason but randomised into different treatment programs in the same unit or even in the same room is difficult and with some ethical problems. Thus, even though the patients were mobilised by physiotherapists in the EMG, the nurses also started to focus on EM in the present study, even though they were not asked to mobilise the patients more than usual. A multi-centre study might be a possibility, but different departments are organised in different ways, and it would be difficult to standardise the treatment completely. Another weakness is the low number of participants. However, despite the associated lack of power, we did find a similar reduction of LOS as in the larger study of Mundy et al ${ }^{14)}$.

In summary, an EM programme compared to usual care appears to reduce the LOS for patients with CAP. Patients with CAP and a CURB65 score of 2 or with COPD seem to gain the most of the EM programme compared to patients who followed the usual care programme. Thus, we suggest that the present study, in addition to the positive findings of the previous RCT, leads to a well-powered multicentre RCT for developing more secure evidence for EM for patients with CAP.

\section{Conflicts of interest}

The authors report no conflicts of interest.

\section{REFERENCES}

1) Niederman MS, McCombs JS, Unger AN, et al.: The cost of treating community-acquired pneumonia. Clin Ther, 1998, 20: 820-837. [Medline] [CrossRef]

2) Carriere KC, Jin Y, Marrie TJ, et al.: Outcomes and costs among seniors requiring hospitalization for community-acquired pneumonia in Alberta. J Am Geriatr Soc, 2004, 52: 31-38. [Medline] [CrossRef]

3) Community-Acquired Pneumonia in Adults: Guidelines for Management. http://eguideline.guidelinecentral.com/i/53989-community-acquired-pneumonia (Accessed May, 2017)

4) Thomsen RW, Riis A, Nørgaard M, et al.: Rising incidence and persistently high mortality of hospitalized pneumonia: a 10-year population-based study in Denmark. J Intern Med, 2006, 259: 410-417. [Medline] [CrossRef]

5) Ruhnke GW, Coca-Perraillon M, Kitch BT, et al.: Trends in mortality and medical spending in patients hospitalized for community-acquired pneumonia: 1993-2005. Med Care, 2010, 48: 1111-1116. [Medline] [CrossRef]

6) Marrie TJ: Community-acquired pneumonia in the elderly. Clin Infect Dis, 2000, 31: 1066-1078. [Medline] [CrossRef]

7) Sharma G, Goodwin J: Effect of aging on respiratory system physiology and immunology. Clin Interv Aging, 2006, 1: 253-260. [Medline] [CrossRef]

8) Klausen HH, Petersen J, Lindhardt T, et al.: Outcomes in elderly Danish citizens admitted with community-acquired pneumonia. Regional differencties, in a public healthcare system. Respir Med, 2012, 106: 1778-1787. [Medline] [CrossRef]

9) Adler J, Malone D: Early mobilization in the intensive care unit: a systematic review. Cardiopulm Phys Ther J, 2012, 23: 5-13. [Medline]

10) Laurent H, Aubreton S, Richard R, et al.: Systematic review of early exercise in intensive care: a qualitative approach. Anaesth Crit Care Pain Med, 2016, 35: 133-149. [Medline] [CrossRef]

11) Schaller SJ, Anstey M, Blobner M, et al. International Early SOMS-guided Mobilization Research Initiative: Early, goal-directed mobilisation in the surgical intensive care unit: a randomised controlled trial. Lancet, 2016, 388: 1377-1388. [Medline] [CrossRef]

12) Pashikanti L, Von Ah D: Impact of early mobilization protocol on the medical-surgical inpatient population: an integrated review of literature. Clin Nurse Spec, 2012, 26: 87-94. [Medline] [CrossRef]

13) Chigira $\mathrm{Y}$, Takai $\mathrm{T}$, Igusa $\mathrm{H}$, et al.: Effects of early physiotherapy with respect to severity of pneumonia of elderly patients admitted to an intensive care unit: a single center study in Japan. J Phys Ther Sci, 2015, 27: 2053-2056. [Medline] [CrossRef]

14) Mundy LM, Leet TL, Darst K, et al.: Early mobilization of patients hospitalized with community-acquired pneumonia. Chest, 2003, 124: 883-889. [Medline] [CrossRef]

15) Hadfield J, Bennett L: Determining best outcomes from community-acquired pneumonia and how to achieve them. Respirology, 2018, 23: 138-147. [Medline] [CrossRef]

16) Lim WS, van der Eerden MM, Laing R, et al.: Defining community acquired pneumonia severity on presentation to hospital: an international derivation and validation study. Thorax, 2003, 58: 377-382. [Medline] [CrossRef]

17) Capelastegui A, España PP, Quintana JM, et al.: Validation of a predictive rule for the management of community-acquired pneumonia. Eur Respir J, 2006, 27: 151-157. [Medline] [CrossRef]

18) Charlson ME, Pompei P, Ales KL, et al.: A new method of classifying prognostic comorbidity in longitudinal studies: development and validation. J Chronic Dis, 1987, 40: 373-383. [Medline] [CrossRef]

19) Charlson M, Szatrowski TP, Peterson J, et al.: Validation of a combined comorbidity index. J Clin Epidemiol, 1994, 47: 1245-1251. [Medline] [CrossRef]

20) Kristensen MT, Andersen L, Bech-Jensen R, et al.: High intertester reliability of the cumulated ambulation score for the evaluation of basic mobility in patients with hip fracture. Clin Rehabil, 2009, 23: 1116-1123. [Medline] [CrossRef]

21) Kristensen MT, Bandholm T, Foss NB, et al.: High inter-tester reliability of the new mobility score in patients with hip fracture. J Rehabil Med, 2008, 40: 589-591. [Medline] [CrossRef]

22) Kristensen MT, Kehlet H: Most patients regain prefracture basic mobility after hip fracture surgery in a fast-track programme. Dan Med J, 2012, 59: A4447. [Medline] 
23) Assessment and treatment of community-acquired pneumonia. http://lungemedicin.dk/fagligt/71-pneumoni.html (Accessed Dec. 2015)

24) Hunter A, Johnson L, Coustasse A: Reduction of intensive care unit length of stay: the case of early mobilization. Health Care Manag (Frederick), 2014, 33: 128-135. [Medline]

25) Fraser D, Spiva L, Forman W, et al.: Original research: implementation of an early mobility program in an ICU. Am J Nurs, 2015, 115: 49-58. [Medline] [CrossRef]

26) Engel HJ, Tatebe S, Alonzo PB, et al.: Physical therapist-established intensive care unit early mobilization program: quality improvement project for critical care at the University of California San Francisco Medical Center. Phys Ther, 2013, 93: 975-985. [Medline] [CrossRef]

27) Houck PM, Bratzler DW, Nsa W, et al.: Timing of antibiotic administration and outcomes for Medicare patients hospitalized with community-acquired pneumonia. Arch Intern Med, 2004, 164: 637-644. [Medline] [CrossRef]

28) Mandell LA, Wunderink RG, Anzueto A, et al. Infectious Diseases Society of America American Thoracic Society: Infectious Diseases Society of America/ American Thoracic Society consensus guidelines on the management of community-acquired pneumonia in adults. Clin Infect Dis, 2007, 44: S27-S72. [Medline] [CrossRef]

29) Confalonieri M, Urbino R, Potena A, et al.: Hydrocortisone infusion for severe community-acquired pneumonia: a preliminary randomized study. Am J Respir Crit Care Med, 2005, 171: 242-248. [Medline] [CrossRef]

30) Meijvis SC, Hardeman H, Remmelts HH, et al.: Dexamethasone and length of hospital stay in patients with community-acquired pneumonia: a randomised, double-blind, placebo-controlled trial. Lancet, 2011, 377: 2023-2030. [Medline] [CrossRef]

31) Siemieniuk RA, Meade MO, Alonso-Coello P, et al.: Corticosteroid therapy for patients hospitalized with community-acquired pneumonia: a systematic review and meta-analysis. Ann Intern Med, 2015, 163: 519-528. [Medline] [CrossRef]

32) Lee JS, Giesler DL, Gellad WF, et al.: Antibiotic therapy for adults hospitalized with community-acquired pneumonia: a systematic review. JAMA, 2016, 315: 593-602. [Medline] [CrossRef]

33) Roberts C, Torgerson D: Randomisation methods in controlled trials. BMJ, 1998, 317: 1301. [Medline] [CrossRef] 